OPEN ACCESS

Edited by:

Carles Canto,

Nestle Institute of Health Sciences

(NIHS), Switzerland

Reviewed by:

Zhibin Wang,

Johns Hopkins University,

United States

Antonius Plagge,

University of Liverpool,

United Kingdom

*Correspondence:

Paul T. Pfluger

paul.pfluger@helmholtz-muenchen.de

Specialty section:

This article was submitted to Epigenomics and Epigenetics,

a section of the journal

Frontiers in Genetics

Received: 07 March 2019 Accepted: 24 September 2019

Published: 11 December 2019

Citation:

Contreras RE, Schriever SC and Pfluger PT (2019) Physiological and Epigenetic Features of Yoyo Dieting and Weight Control.

Front. Genet. 10:1015.

doi: 10.3389/fgene.2019.01015

\section{Physiological and Epigenetic Features of Yoyo Dieting and Weight Control}

\author{
Raian E. Contreras ${ }^{1,2,3,4}$, Sonja C. Schriever ${ }^{1,2,3}$ and Paul T. Pfluger ${ }^{1,2,3,4 *}$ \\ ${ }^{1}$ Research Unit Neurobiology of Diabetes, Helmholtz Zentrum München, Neuherberg, Germany, ${ }^{2}$ Institute for Diabetes and \\ Obesity, Helmholtz Zentrum München, Neuherberg, Germany, ${ }^{3}$ German Centre for Diabetes Research (DZD), Neuherberg, \\ Germany, ${ }^{4}$ Neurobiology of Diabetes, TUM School of Medicine, Technische Universität München, Munich, Germany
}

Obesity and being overweight have become a worldwide epidemic affecting more than 1.9 billion adults and 340 million children. Efforts to curb this global health burden by developing effective long-term non-surgical weight loss interventions continue to fail due to weight regain after weight loss. Weight cycling, often referred to as Yoyo dieting, is driven by physiological counter-regulatory mechanisms that aim at preserving energy, i.e. decreased energy expenditure, increased energy intake, and impaired brain-periphery communication. Models based on genetically determined set points explained some of the weight control mechanisms, but exact molecular underpinnings remained elusive. Today, gene-environment interactions begin to emerge as likely drivers for the obesogenic memory effect associated with weight cycling. Here, epigenetic mechanisms, including histone modifications and DNA methylation, appear as likely factors that underpin longlasting deleterious adaptations or an imprinted obesogenic memory to prevent weight loss maintenance. The first part summarizes our current knowledge on the physiology of weight cycling by discussing human and murine studies on the Yoyo-dieting phenomenon and physiological adaptations associated with weight loss and weight re-gain. The second part provides an overview on known associations between obesity and epigenetic modifications. We further interrogate the roles of epigenetic mechanisms in the CNS control of cognitive functions as well as reward and addictive behaviors, and subsequently discuss whether such mechanisms play a role in weight control. The final two parts describe major opportunities and challenges associated with studying epigenetic mechanisms in the CNS with its highly heterogenous cell populations, and provide a summary of recent technological advances that will help to delineate whether an obese memory is based upon epigenetic mechanisms.

Keywords: weight loss, Yoyo dieting, CNS, epigenetic mechanisms, obesogenic memory

\section{THE PHYSIOLOGY OF WEIGHT CYCLING}

Obesity and its deadly comorbidities such as type-2 diabetes (T2D), cardiovascular diseases or some forms of cancer are health problems of the first order (World Health Organization, 2018). In 2016, more than 1.9 billion adults and 340 million children were classified as overweight or obese. However, efforts to curb the ever-increasing obesity pandemic have largely failed. 
Non-surgical therapies against obesity are ineffective for a large proportion of obese individuals. Studies in overweight and obese individuals undergoing weight loss reported that only $20 \%$ of the participants were able to maintain the weight loss long term (McGuire et al., 1999; Wing and Phelan, 2005). Thus, consistent with reports that $2-6 \%$ body weight regain can already reverse the benefits of losing $\geq 10 \%$ body weight (Kroeger et al., 2014), novel strategies against the regain in weight are of utmost need.

\section{Defining Successful Weight Loss}

A successful weight loss maintainer is defined as an individual who voluntarily decreases $\geq 10 \%$ of the initial body weight and keeps the lost weight for $\geq 1$ year (Wing and Hill, 2001). Most individuals fail in maintaining their weight loss due to weight cycling, often referred to as Yoyo dieting. Weight regain often starts within the first year, and the pre-intervention weight is reached or even surpassed in the subsequent 2 to 5 years (Anderson et al., 2001; Weiss et al., 2007). Lean individuals that were voluntarily overfed with $50 \%$ additional calories for 3 days showed decreased pre-meal hunger and increased postmeal satiety (Cornier et al., 2004). In obese individuals that underwent weight loss, overfeeding did not diminish hunger or increase satiety. This absence of compensatory changes in hunger and satiety upon overfeeding likely contributes to an increased propensity for weight regain in obese individuals that undergo weight loss (Cornier et al., 2004). Overall, only 11\% of the individuals with early-onset weight re-gain can achieve a subsequent body weight loss within that first year (Wing and Phelan, 2005).

Limiting or preferentially avoiding weight cycling in the first year after weight loss appears to be crucially important for a sustainable long-term weight maintenance, as evidenced by a study that reported a $50 \%$ decrease in the risk for subsequent weight regain in individuals that managed to maintain their successful weight loss for 2 years (Wing and Phelan, 2005). Most therapeutic strategies against this first-year Yoyo-dietingeffect are built upon nutritional interventions, i.e. calorie and/ or fat restriction, ketogenic diets or intermittent fasting. These strategies can be highly efficacious, as evidenced by the National Weight Control Registry (NWCR), an ongoing longitudinal study of more than 4,000 successful weight loss maintainers ( $\geq 13.6 \mathrm{~kg}$ (30 lb) for $\geq 1 \mathrm{y}$ ) (Wing and Phelan, 2005; Bond et al., 2009). Strict adherence to weight loss maintenance strategies appears to be key for $89 \%$ of these successful weight loss maintainers, which includes both high levels of physical activity and consuming a low calorie, low fat diet.

\section{Physiological Adaptations to Weight Loss}

Body weight maintenance requires a dynamically adjusted homeostasis of energy intake and energy expenditure. A chronically negative energy balance would lead to the depletion of energy stores, a chronically positive energy balance to an undesired accumulation of energy surplus (Maclean et al., 2011). Unfortunately, in our modern Westernized societies a chronically positive energy balance is the norm for many. Stressful and sedentary lifestyles are combined with an overconsumption of highly palatable and energy-dense food enriched in saturated fats and processed sugars. The excess of energy intake leads to the development of overweight and ultimately to obesity (Melby et al., 2017). Becoming obese does not occur overnight. It takes a considerable amount of time under constant obesogenic pressure to develop adiposity. This length in time also allows an individual's biology to adapt to the new state of obesity (Corbett et al., 1986). This adaptive process defines a state in which energy expenditure and high energy intake are balanced to defend the newly gained weight and adiposity (Corbett et al., 1986; Kirchner et al., 2012).

To lose weight, obese individuals often undergo severe caloric restriction, i.e. they reduce their overall energy intake to create a negative energy balance (Rosenbaum et al., 2010). In consequence, the body readily adapts by a rapid decrease in the total daily energy expenditure (TDEE) to preserve energy and restore homeostasis (Rosenbaum et al., 2008). This decrease in TDEE can nevertheless be disproportionate to the decrease in energy intake, as evidenced by a report that showed 25\% lower TDEE in weight-reduced compared to never-obese individuals (Leibel et al., 1995). By the end of a weight loss period, all three main components of TDEE are reduced, i.e. the thermic effect of food required for the digestion and absorption of ingested calories (Maclean et al., 2011), activity-induced energy expenditure including non-exercise activity thermogenesis (NEAT) and exercise energy expenditure (EEE) (Goldsmith et al., 2010; Hames et al., 2016), and the resting metabolic rate (RMR) (Melby et al., 1990; Astrup et al., 1999; Doucet et al., 2001). The reduction in TDEE after profound weight loss can last for several years (Camps et al., 2013) and impairs the long-term maintenance of weight loss in both mice and men (Hill et al., 1987; Froidevaux et al., 1993; Maffei et al., 1995; Doucet et al., 2001; MacLean et al., 2004). For instance, participants of the TV show "The Biggest Loser" showed a persistent decrease in their RMR even 6 years after the weight loss, which likely contributed to the regain in body weight in all but one of the 14 subjects (Fothergill et al., 2016).

The arguably most important factor that determines weight maintenance vs. weight re-gain after weight loss is food intake. Our ingestive behavior is built upon parallel and complementary mechanisms that integrate peripheral signals from circulating hormonal factors for hunger or fullness with homeostatic feeding circuitry in the hypothalamus and brain stem and hedonic processes that are partially beyond our cognitive control (Waterson and Horvath, 2015). Weight loss by calorie restriction is associated with increased hunger and a strongly increased reward value of food (Rosenbaum et al., 2010; Burger and Stice, 2011; Blundell et al., 2012; Caudwell et al., 2013). Notably, the sensation of increased hunger appears to persist beyond the phase of rapid weight loss; previously obese mice that had been subjected to rapid weight loss by calorie restriction showed hyperphagia when re-fed ad-libitum with chow fed diet, leading to accelerated weight re-gain even when compared to never-obese mice subjected to a HFD (Kirchner et al., 2012). In contrast, when diet-induced obese mice were subjected to slow weight loss induced by ad libitum low calorie diet feeding, hyperphagia was absent and the mice maintained their reduced body weight (Fischer et al., 2018). 


\section{Hormonal Factors Guide Our Compensatory Response to Weight Loss}

Mechanistically, weight loss was shown to induce a profound deregulation of circulating nutrients such as glucose or free fatty acids which can act as signaling moieties in CNS centers governing energy and glucose homeostasis (Lam et al., 2005; He et al., 2006). Similarly, weight loss and a negative energy balance altered the secretion of circulating hormones such as the orexigenic ghrelin or the anorexigenic leptin, insulin, GLP-1, CCK and PYY (Maffei et al., 1995; Näslund et al., 2000; Crujeiras et al., 2010; Rosenbaum et al., 2010; Maclean et al., 2011; Melby et al., 2017). These endocrine adaptations to a chronically negative energy balance are believed to drive hyperphagia and the frequency and/or the size of meals in both humans and rodents (Kirchner et al., 2012; Karatsoreos et al., 2013; Catenacci et al., 2014). Such altered levels of circulating hormones that facilitate weight regain appear to persist for at least 1 year (Sumithran et al., 2011; Camps et al., 2013). Accordingly, numerous attempts have tried to utilize hormone replacement interventions to combat weight-loss induced physiological adaptations, i.e. the increase in hunger and decrease in energy expenditure (Kelesidis et al., 2010; Kissileff et al., 2012; Trujillo et al., 2015; Vodnik et al., 2016). For instance, leptin replacement was considered as putative antidote against weight regain based on a clinical study that showed promising benefits of leptin replacement in weight loss patients, i.e. increases in sympathetic nerve system activity and a restoration of skeletal muscle work efficiency (Rosenbaum et al., 2005). Similarly, mice undergoing leptin replacement therapy displayed an increased expression of the anorexigenic neuropeptide proopiomelanocortin and a normalized energy homeostasis and weight maintenance (Chhabra et al., 2016). However, these reports stand in contrast to a chronic leptin infusion study in mice which suggested that the weight maintenance is independent from leptin (Ravussin et al., 2014).

In summary, weight loss is associated with adaptive physiological processes that evolved to defend body weight from weight loss, i.e. increased hunger and food reward behavior and decreased energy expenditure. The signals that drive these changes may be hormonal, but their exact nature remains elusive. How weight loss is achieved appears to be of crucial importance. If the negative energy balance stems from severe caloric restriction, strong counter-regulatory stimuli come to play. A slow weight loss, e.g. based on switching from an obesogenic to a healthier diet, seems to evade some of the adaptive responses to fully reverse obesity. However, at current this paradigm of fast vs. slow weight loss still lacks solid experimental proof and a theoretical foundation.

\section{The Set-Point Theory Postulates an Obesogenic Memory Against Weight Loss}

The long persistence of metabolic adaptations in response to rapid weight loss in obese individuals raises a critical question: is there an acquired obesogenic memory that drives weight regain in order to maintain a previous status quo? Many hypotheses have been postulated regarding 'body weight points' and acting compensatory mechanisms. One of the most debated ones, the set-point or lipostatic theory, was first introduced by Kennedy in the early 50s (Kennedy and Sterling, 1953). A fat derived signal, conveying the status of fat-depots, is sensed by the brain where it is compared to a target level, in order to trigger compensatory mechanisms upon any disturbance. This negative feedback loop was strongly supported by the discovery of leptin (Zhang et al., 1994), genetic mutations in the leptin gene and the MC4R family (Farooqi et al., 1999; Farooqi and O'Rahilly 2008) and the description of leptin resistance in diet-induced obese mice and obese humans (Maffei et al., 1995; Schwartz et al., 1996; Halaas et al., 1997; Friedman 2016). However, in this past decade several studies questioned the existence of leptin resistance (Ottaway et al., 2015; Harrison et al., 2018; Pan and Myers Jr, 2018). Moreover, leptin infusion studies in mice revealed that hyperleptinemia is unlikely to define an obese body weight set point (Ravussin et al., 2014).

The set-point theory remains to be controversially discussed, with both reports corroborating a set point in human and animal studies, and multiple reports that find no experimental evidence for a set point (Halaas et al., 1997; Carhuatanta et al., 2011; Ravussin et al., 2014; Chhabra et al., 2016; Jansson et al., 2018). Models describing single factors fail to fully explain the observed weight cycling phenomenon. As an alternative concept, the dual intervention point theory uses two independent upper and lower weight levels as boundaries for active regulation. A lower weight boundary is indispensable to avoid starvation in times of low energy availability, and compensatory mechanisms that counteract starvation and weight loss are evolutionary conserved and privileged. An upper weight level was delimited by the risk of predation that required a certain leanness and fitness. However, around 2 million years ago early humans evolved enough to partially release the risk for predation (Speakman, 2018), which liberated the upper weight level and mechanisms that prevented from excessive weight and fat accumulation. The phenomenon, also described as genetic drift, has been suggested as a major driver for the obesity epidemic (Speakman, 2007).

\section{Resetting the Obesogenic Memory by Bariatric Surgery}

At current, there is only one efficient therapeutic strategy against obesity: bariatric surgery. In essence, bariatric surgery is the reorganization of the gastrointestinal track that not only reverses severe obesity, but also helps patients with moderate degrees of obesity and difficult-to-control metabolic disorders (Lutz and Bueter, 2014). Two of the most commonly applied bariatric surgeries, Roux-en-Y gastric bypass (RYBG) and vertical sleeve gastrectomy (VSG), successfully achieve approximately $25 \%$ weight loss within the first year. Contrary to the persistently decreased RMR observed in weight loss patients undergoing calorie restriction, RYGB individuals showed a temporarily reduced RMR which resolved to normal after 1 year (Knuth et al., 2014; Fothergill et al., 2016). A comparison between successful weight losers via surgical or non-surgical interventions confirmed that weight loss maintenance is achievable to the same degree in both cases, but surgical-patients require less physical activity and dietary restraint (Bond et al., 2009). Similarly, weight 
regain mechanisms such as increased hunger and decreased energy expenditure were absent in RYGB rodent models (Bueter et al., 2010; Hao et al., 2013).

Mechanisms mediating the beneficial effects of bariatric surgery are largely elusive, but first evidence points to an improved communication between peripheral organs and the CNS, possibly mediated via hormones, biles acids and/or neuronal pathways. For instance, mice with a deficiency for farnesoid X receptor (FXR), a transcription factor activated by bile acids, were reported to be unresponsive to bariatric surgery (Ryan et al., 2014). FXR KO mice showed full post-surgical weight regain 11 weeks after VSG surgery, while wildtype littermates showed sustained weight loss (Ryan et al., 2014). In both humans and rodents, bariatric surgery alters the composition and concentration of bile acids (Patti et al., 2009; Kohli et al., 2013; Myronovych et al., 2014). Accordingly, it appears possible that benefits of bariatric surgery such as improved glucose disposal and lipid homeostasis are in part mediated by bile acids and FXR activation, potentially driven via an increase in post-prandial FGF19 secretion (Schaap, 2012; Wu et al., 2013). Bariatric surgery is furthermore associated with profound alterations in the post-prandial release of anorexigenic (e.g. GLP-1 and PYY) and orexigenic (ghrelin) gastrointestinal hormones. These changes in the secretion are often discussed as likely mechanisms for metabolic benefits of bariatric surgery, as evidenced by the lack of effects of bariatric surgery in mice deficient for PYY (le Roux et al., 2006). However, studies in GLP1 and ghrelin wild-type and knockout mice showed comparable weight loss after bariatric surgery, respectively (Chambers et al., 2013; Wilson-Pérez et al., 2013; Mokadem et al., 2014; Ye et al., 2014). Leptin replacement therapy has recently been shown to improve the metabolic response of leptin-deficient $\left(\mathrm{Lep}^{\mathrm{ob}}\right)$ mice to RYGB surgery (Hao et al., 2015). In humans, the decrease in circulating leptin levels is smaller after RYGB ( 50\%) compared to lifestyle interventions ( 100\%) (Knuth et al., 2014). Thus, an improvement in leptin sensitivity seems like a tempting hypothesis, but studies in VSG-operated rats showed no difference in leptin sensitivity when compared to pair-fed control rats (Stefater et al., 2010). Notwithstanding, the melanocortin system and its melanocortin 4 receptor (MC4r) are required for the benefits of RYGB in energy expenditure, body weight and glucose metabolism in mice (Hatoum et al., 2012; Mokadem et al., 2014). Similarly, human carriers of a specific MC4R gene variant [MC4R(I531L)] showed an improved outcome to bariatric surgery with a better metabolic status (Zechner et al., 2013). Overall, our understanding on whether peripheral hormones mediate the effects of bariatric surgery, either as single entities or in combination, is still incomplete. Additional evidence points towards a direct interaction with CNS melanocortin signaling, but details remain to be clarified.

\section{THE EPIGENETICS OF OBESITY AND WEIGHT CYCLING}

Epigenetic modifications are reversible alterations in gene transcription without alterations in the underlying genomic DNA sequence. Current epigenetic modifications include 1) DNA methylation, i.e. the covalent attachment of a methyl group to the 5 position of a cytosine $(5 \mathrm{mC})$ or its conversion into 5-hydromethylcytosine (5hmC) in $\mathrm{CpG}$ and non-CpG islands; 2) histone posttranslational modifications (HPTM), i.e. the addition of a variety of molecules to the protruding tails of the core histones and 3) RNA interference mediated posttranscriptional modifications (Figure 1). Together, epigenetic mechanisms modulate transcriptional programs by promoting chromatin remodeling around genomic regions that can enhance or inhibit gene transcription (Bird, 1999; Egger et al., 2004; Day and Sweatt, 2011; Smallwood and Kelsey, 2012).

\section{Obesity Is Associated With Distinct Epigenome Signatures in Peripheral Tissues}

Epigenetic modification can be self-perpetuating and heritable, as shown by multiple transgenerational studies on inheritable traits (Egger et al., 2004; Seki et al., 2012; Dalgaard et al., 2016). Such evidence supporting the role of epigenetics in developmental programming of obesity has for instance been demonstrated in whole blood of patients that were born to women exposed periconceptually to severe undernutrition in the Dutch Hunger during World War II (Heijmans et al., 2008). At the age of 58 years, these patients showed reduced methylation of the imprinted gene IGF2 (Insulin-like growth factor 2) and a higher risk of obesity or glucose intolerance (Ravelli et al., 1998; Stein et al., 2007). Animal studies confirmed the impact of under- or overnutrition before or during gestation on the epigenome and the phenotype of the offspring (Zhang et al., 2010; Ainge et al., 2011; Nicholas et al., 2013).

Recent studies further demonstrate the importance of reversible non-heritable epigenetic modifications in adulthood and in post-mitotic and fully differentiated cells (Renthal et al., 2007; Day and Sweatt, 2011; Lester et al., 2011; Vucetic et al., 2011; Vucetic et al., 2012). Associations between obesity and epigenetic changes, mostly in DNA methylation, have for instance been reported for blood cells such as peripheral blood leukocytes (PBLs) as well as muscle, adipose tissue, placenta and colon. Candidate-based gene methylation studies have identified multiple differentially methylated genes in blood and peripheral tissues of obese compared to lean individuals. Reduced methylation of tumor necrosis factor (TNFa) (Hermsdorff et al., 2013) and the adipocyte-derived hormone leptin (LEP) (Obermann-Borst et al., 2013) were found in blood of obese humans, whereas methylation of circadian rhythm protein CLOCK : BMAL1 (Circadian Locomotor Output Cycles Kaput and aryl hydrocarbon receptor nuclear translocatorlike) was increased by adiposity in PBLs (Milagro et al., 2012). In muscle of obese humans, methylation of pyruvate dehydrogenase kinase 4 (PDK4) was decreased but methylation of PPAR $\gamma$ coactivator 1 alpha $(P G C 1 \alpha)$ was increased compared to lean individuals (Barres et al., 2013). Recently, three lines of evidence-epigenetic dysregulation following high fat diet in mouse, epigenetic directional consistency in humans, and some evidence for clinical risk of T2D-were combined to identify epigenetic mechanisms in adipose tissue that most likely have 


\section{CNS centres of body weight control Cellular heterogeneity within CNS centers}

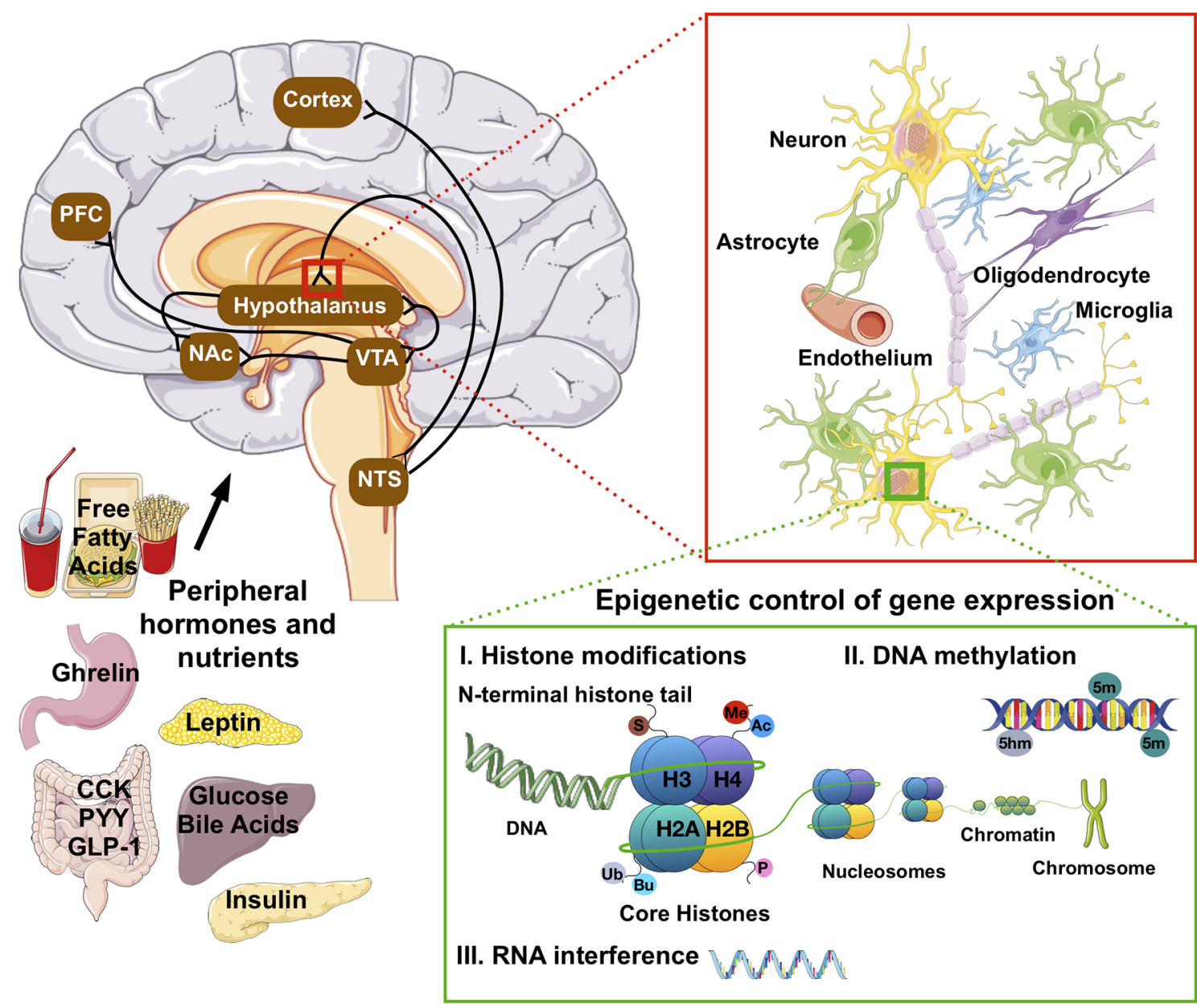

FIGURE 1 | Anatomical, cellular and molecular heterogeneity in the CNS control of food intake and energy homeostasis. Hormonal and nutrient cues from peripheral tissues signal the state of our dietary and energetic requirements to brain regions that govern our homeostatic and hedonic control of food intake and body weight. These neuronal circuits are deeply interconnected, and embedded within a network of vascular cells and highly diverse glial cell populations ranging from astrocytes to microglia and oligodendrocytes. The lineages and identities of these highly diverse neuronal and glial subpopulations are in part driven by variations in the epigenome, i.e. epigenetic changes such as DNA methylation, histone post-translation modifications (Ac, acetylation; Me, methylation- Ub, ubiquitination; P, propionylation; Bu, butyrylation and S, sumoylation) and RNA-mediated post-translational interference. In fully developed, post-mitotic neurons, epigenetic mechanisms were further shown to influence reward behaviors and cognitive functions. PFC, pre-frontal cortex; NAc, nucleus accumbens; VTA, ventral tegmental area; NTS, nucleus of the solitary tract; CCK, cholecystokinin; PYY, peptide YY; GLP-1, glucagon-like peptide 1.

a functional implication in the pathogenesis of obesity-driven T2D (Multhaup et al., 2015). The identified candidate genes MRTFA (myocardin related transcription factor A), PLEKHO1 (pleckstrin homology domain containing O1) and TNFAIP8L2 (TNF alpha induced protein 8 like 2) were all hypomethylated in HFD-fed mice and obese humans and had increased gene expression. Moreover, overexpression of these genes in cell culture adipocytes decreased uptake of glucose in response to insulin which is consistent with an increased insulin resistance commonly observed in obesity and diabetes (Multhaup et al., 2015). However, most of these studies are cross-sectional and epigenetic changes were recorded at the same time-point as the obese phenotype. Accordingly, to determine whether epigenetic modifications such as DNA methylation marks are a cause or consequence of obesity remains a challenge in the field (van Dijk et al., 2015).

The study of epigenetic mechanisms in weight control is further complicated by the recent finding that DNA methylation profiles are instable in adulthood and affected by diet, exercise and weight loss interventions (Milagro et al., 2011; Rönn et al., 2013; Multhaup et al., 2015). DNA methylation profiles of blood cells from obese patients, successful weight loss maintainers and never-obese individuals showed marked differences in the genes BDNF (brain derived neurotrophic factor), RIR1 (ribonucleotide reductase catalytic subunit M1), and TUBA3C (tubulin alpha 3c) (Huang et al., 2015). Interestingly, after weight loss surgery muscle DNA methylation profiles of formerly obese individuals became more similar to those of the lean controls 
(Barres et al., 2013) indicating that some methylation marks are rather a consequence of than a predisposition for obesity. It was further shown that adipose tissue DNA methylation profiles can not only be modulated by exercise (Rönn et al., 2013) but can also be used to predict the response to weight loss interventions in humans (Bouchard et al., 2010; Cordero et al., 2011). In the liver of diet-induced obese (DIO) mice, treatment with metformin, a widely used drug against $\mathrm{T} 2 \mathrm{D}$, reversed the increased histone methylation (H3K36me2) (Nie et al., 2017) indicating that pharmacological interventions can also affect epigenetic mechanisms at the level of the chromatin.

Overall, growing evidence suggests that epigenetic changes are mechanistically linked with the regulation of body weight. However, causality for this phenomenon remains to be provided. Moreover, whether any of the recently identified genes contribute to the heritability of obesity has not been established. Here, the recent identification of reduced expression of an imprinted gene network including the genes neuronatin (Nnat), paternally expressed 3 (Peg3), cyclin-dependent kinase inhibitor 1C (Cdkn1c) and pleiomorphic adenoma gene-like 1 (Plagl1) in the obese population provided genetic evidence that mechanisms exist in mammals to canalize developmental and phenotypic outcomes along discrete trajectories (Dalgaard et al., 2016).

\section{Epigenetic Mechanisms Regulate the CNS Control of Behavior}

Post-mitotic epigenetic modification are an integral process for neurons during memory formation and learning. Memory consolidation during contextual fear learning increased global di-methylation of histone 3 lysine 9 (H3K9me2) in the CA1 region of the hippocampus and the lateral entorhinal cortex, with marked transcriptional regulation on genes like $B d n f$, Fos, Dnmt3a and Zif268 at both the level of the promoter and mRNA expression(Gupta-Agarwal et al., 2012). Modifications of the H3K9me2 histone lysine methyltransferase G9a (H/ KMTs-G9a) or demethylase LSD1 (H/KDMs-LSD1) in the lateral amygdala (LA) were shown to impair or enhance fear memory consolidation, respectively (Gupta-Agarwal et al., 2014). Similarly, DNA methylation contributed to maintain long-term (remote) memories (Miller et al., 2010). Persistent DNA hypomethylation in CpG islands at the $B d n f$ locus was functionally linked with the specific upregulation of exons I and IV in the adult hippocampus and a consolidation of fear memory (Lubin et al., 2008; Mizuno et al., 2012).

Next to the effects on memory formation and learning, epigenetic modifications in neurons have been associated with cognitive impairment in response to psychostimulant and drug abuse, and with a direct impact on reward behavior. Upon chronic cocaine exposure, histone deacetylase 5 (HDAC5) in the nucleus accumbens (NAc) was shown to mitigate H3-hyperacetylation at gene promoters that ultimately lead to gene activation (i.e. NK1R upregulation) and the promotion of reward behaviors within a conditioned place preference paradigm (Renthal et al., 2007). Methamphetamine intake promoted hydroxylation and hypomethylation in CpG-rich regions in the promoter and intragenic sequences of the $\mathrm{Crh} / \mathrm{Crf}$ and Avf genes in the NAc (Jayanthi et al., 2018). The increased expression of both neuropeptide genes is associated with prolonged neuroendocrine responses like hypersecretion of plasma adrenocorticotropine hormone (ACTH) and cortisone after acute amphetamine injections (Bisagno and Cadet, 2014). In the medial prefrontal cortex (mPFC), methamphetamine increased the expression of Drd1 and Grin 1 by augmenting H4ac enrichment at their promoter regions but decreased expression of Hcrtr2 by reducing $\mathrm{H} 3 \mathrm{ac}$ enrichment at its promoter region (González et al., 2018). Overall, these studies highlight the role of post-mitotic epigenetics in conveying long-term adaptations to the environment.

\section{Epigenetic Mechanisms in the CNS Control of Food Intake and Body Weight}

Given the involvement of epigenetic mechanisms in cognition and reward behaviors, it seems plausible that epigenetic mechanisms may also be linked to the CNS hedonic control of food intake and food reward behaviors, and in general to the development of obesity in both the CNS and peripheral tissues. However, few studies have addressed whether postmitotic epigenetic modifications upon chronic exposure to an obesogenic environment exist within the CNS, and whether they play a functional role in the etiology of metabolic dysfunction. For peripheral tissues, such distinct epigenome signatures have been reported, as outlined above. For the CNS, we know that multiple epigenetic regulators are expressed in brain regions involved in feeding behaviors and energy homeostasis such as the hypothalamus, the midbrain or the brain stem. However, whether they are functionally involved in the CNS regulation of energy and glucose metabolism largely remains to be determined.

Obesity-induced changes in the epigenetic marks of the CNS were investigated in a study by Vuceti et al., (2011) who correlated a decrease in $\mu$-opioid receptor gene expression in reward circuitry of the ventral tegmental area (VTA), NAc and PFC with epigenetic repressive marks such as increased DNA methylation in the promoter and binding sequence of methyl CpG binding protein 2 (MeCP2), increased $\mathrm{H} 3 \mathrm{~K} 9$ methylation and decreased $\mathrm{H} 3$ acetylation in obese mice compared to lean controls. Similarly, DIO mice showed a reduced DNA methylation in the tyrosine hydroxylase $(\mathrm{TH})$ and dopamine transporter (DAT) in the hypothalamus which was correlated with increased expression of both mRNAs (Vucetic et al., 2012). The exact opposite pattern on DNA methylation and mRNA expression of DAT and TH was evidenced in the VTA. Moreover, dopamine receptors D1 and D2 were also decreased in the striatum which complemented the dopaminergic dysfunction in obesity (Alsiö et al., 2010).

Overall, there is emerging evidence that environmental changes in response to an obesogenic environment can induce epigenetic modifications in multiple tissues and cell types. Several studies suggest an impact of epigenetic modifications on reward circuitry involved in our hedonic control of feeding. Nonetheless, at current there is no evidence on whether and how epigenetic mechanisms can converge into a compulsive phenotype imprinted in an obesogenic environment. 


\section{OPPORTUNITIES AND CHALLENGES IN STUDYING CNS EPIGENETICS}

The relative lack of studies on epigenetic mechanisms in the CNS control of food intake and metabolism is based on a number of factors such as the complexity of the brain with its high cell heterogeneity. Nonetheless, at current our knowledge on the epigenome and transcriptome of neuronal as well as glial CNS subpopulations is propelled by technological advances in next generation sequencing and computational analysis, as outlined below.

\section{Cellular Heterogeneity in CNS Control Centers of Body Weight Homeostasis}

Numerous neuronal subpopulations are part of a complex and incompletely understood network that orchestrates our metabolic homeostasis (Figure 1). Next to neurons, there is a multitude of glial cell types, ranging from oligodendrocyte species to astrocyte and microglial subpopulations. These are embedded within a dense network of blood vessels with endothelial cells and pericytes, and form a functional blood brain barrier interface that plays a vital role in nutrient (e.g. glucose) and endocrine (e.g. insulin and leptin) sensing and the CNS control of feeding behavior and energy homeostasis as well as brain glucose uptake (Kim et al., 2014; García-Cáceres et al., 2016).

All these cell types contain the same copy of the genome, but they greatly differ in the spatial and temporal expression of defined portions of the genome that define and drive the lineage of the respective cellular sub-population. Isolating RNA or DNA from a specific CNS cell type nonetheless remains a major experimental challenge due to the fragility and high interconnection. Accordingly, most of the research on adult CNS has been limited to the analysis of epigenetic variations in bulk brain tissue. Pooling multiple cell types together likely masks cell type-specific variations and requires complex bioinformatical deconvolution algorithms. Gene co-expression modules, i.e. co-expressed genes of a cell type that are highly correlated to the proportion of the cell type in a sample and deduced from a large number of independent datasets, permit to determine core transcriptional features of specific cell-types (Kelley et al., 2018). Additional algorithms such as MetaVIPER (Ding et al., 2018) and machine learning tools to leverage large data sets will help to overcome the challenges associated with cellular heterogeneity (Tritschler et al., 2017; Eraslan et al., 2019; Fischer et al., 2019). However, whether they are universally applicable to specific brain-region and cell-type analyses remains underexplored.

\section{Novel Tools to Isolate and Study Defined CNS Subpopulations}

Several approaches can be used to dissociate and isolate specific CNS populations for downstream epigenome analyses. Fluorescence activated cell sorting (FACS) and magnetic activated cell sorting (MACS) in combination with specific antibody panels are now used since more than 30 years to isolate the three main brain cell types, i.e. neurons, astrocytes and microglia (Paden et al., 1986; Martin et al., 2017). However, working with fresh tissue requires enzymatic dissociation and a time-consuming sorting, which can result in low cell recovery and artefactual stress responses and gene expression patterns. Embryonal and neo-natal brains appear to be more suitable for FACS/MACS of whole cells, but the approach has also been used in adult rodents (García-Cáceres et al., 2016; Paeger et al., 2017). For instance, in post-natal forebrains, transcriptome profiling of FACS-sorted neurons, astrocytes and oligodendrocytes revealed common metabolic pathways, but also a high variety and several highly dissimilar sub-clusters within the glial cell class (Cahoy et al., 2008). Differences in transcriptome profiles are likely reflected by differences in gene regulation, as highlighted by specific cell-type DNA methylation profiling in hypothalamic post-natal neurons versus glia (Li et al., 2014).

The dissociation and isolation of nuclei from frozen or fixed tissue has shown the potential to overcome the challenges associated with isolating intact cells from fresh tissue (Jiang et al., 2008; Krishnaswami et al., 2016). Nuclei are stable and largely devoid of cytosolic factors that interfere with epigenomic processes. Moreover, their protein-coding transcript content is highly reminiscent of the content in whole cells (Barthelson et al., 2007; Solnestam et al., 2012; Grindberg et al., 2013). Nuclei further express specific membrane-bound antigens such as NeuN or OLIG2 which mark them as neuronal or oligodendrocyte nuclei, respectively (Xu et al., 2018b). By applying specific antibodies and FACS or MACS, these nuclear subpopulations can be sorted and characterized from adult brain tissues. This approach can further be advanced by using genetically engineered mice with a nuclear membrane-bound fusion protein (Sun1-sfGFP-Myc) that is expressed under the control of Cre recombinase (Deal and Henikoff, 2011; Mo et al., 2015). The fusion protein on the nuclear membrane is only expressed in Cre-positive CNS sub-populations, and nuclei with the fusion protein can be isolated from brain areas by applying the protocol for the isolation of nuclei tagged in specific cell types (INTACT). This INTACT protocol allows to isolate both DNA and RNA from the nuclei of rare CNS sub-populations for a full transcriptome and epigenome profiling (Mo et al., 2015). An alternative approach, the translating ribosome affinity purification (TRAP) technology, is directed towards the selective enrichment of RNA bound to ribosomes of genetically tagged CNS subpopulations (Doyle et al., 2008). The TRAP method is based on a genetic mouse model with an eGFP-L10a ribosomal fusion protein under the control of Cre recombinase, and is restricted to the analysis of the translatome within Cre-positive cell populations (Heiman et al., 2008).

Next to recent advances in methods and genetic tools to isolate CNS sub-populations, downstream next generation sequencing (NGS) applications have undergone major technological improvements to also allow the transcriptome and epigenome profiling of low input material. Regular high-throughput NGS protocols continue to require millions of cells, which goes beyond the typical yield when working with small brain regions and rare cellular CNS sub-populations. However, in the last years single cell RNAseq became a new standard in the field and is now widely used to interrogate cellular identities and lineages of whole 
organisms (Plass et al., 2018), whole peripheral organs (Tritschler et al., 2017; Angelidis et al., 2019) or small brain regions (Zeisel et al., 2015; Lam et al., 2017; Moffitt et al., 2018). Multiple efforts are further underway to enable single cell epigenome profiling (Kelsey et al., 2017; Lake et al., 2018; Wen and Tang, 2018)) but they are not yet reaching the informational depth of scRNAseq. Nonetheless, new NGS methods such as single cell ATACseq (Jia et al., 2018), low-input whole-genome bisulfite sequencing (Peat and Smallwood, 2018), Cut\&Run (Skene and Henikoff, 2017) and (HT-)ChIPmentation (Schmidl et al., 2015; Gustafsson et al., 2019) can bridge the gap between single cell resolution and bulk tissue profiling, and enable to interrogate the transcriptome and epigenome of rare CNS sub-population in unprecedented detail.

\section{SUMMARY AND OUTLOOK}

Losing weight and remaining lean is a very hard task for most of the overweight and obese individuals (Wing and Phelan, 2005). The principal issue is not losing weight per se, but rather the fight against physiological adaptions directed against keeping the lost weight (Maclean et al., 2011; Dulloo and Montani, 2015). Bariatric surgery is currently the only option to sustainably lose weight, but its mechanisms are largely unclear (Knuth et al., 2014). The CNS with homeostatic control centers within the hypothalamus and hindbrain appears to be key for the maintenance of body weight. Homeostatic brain centers sense and integrate a plethora of peripheral and environmental messages to adequately regulate food intake and energy homeostasis (Waterson and Horvath, 2015). Of similar importance are hedonic control centers and reward circuitry within the limbic system, which orchestrate behavioral and biological responses such as food seeking, food reward and food perception behaviors, memory formation and cognition. These brain regions are susceptible to epigenetic reprogramming (Alsiö et al., 2010; Miller et al., 2010; Gupta-Agarwal et al., 2014; Jayanthi et al., 2018), and are likely targets for epigenetic modifications induced by obesity. Future studies should unravel whether an epigenetic memory for obesity exists within these CNS centers, and whether it is functionally linked to the regulation of body weight

\section{REFERENCES}

Ainge, H., Thompson, C., Ozanne, S. E., and Rooney, K. B. (2011). A systematic review on animal models of maternal high fat feeding and offspring glycaemic control. Int. J. Obes. 2005 35, 325-335. doi: 10.1038/ijo.2010.149

Alsiö, J., Olszewski, P. K., Norbäck, A. H., Gunnarsson, Z. E. A., Levine, A. S., Pickering, C., et al. (2010). Dopamine D1 receptor gene expression decreases in the nucleus accumbens upon long-term exposure to palatable food and differs depending on diet-induced obesity phenotype in rats. Neuroscience 171, 779787. doi: 10.1016/j.neuroscience.2010.09.046

Anderson, J. W., Konz, E. C., Frederich, R. C., and Wood, C. L. (2001). Long-term weight-loss maintenance: a meta-analysis of US studies. Am. J. Clin. Nutr. 74, 579-584. doi: 10.1093/ajcn/74.5.579

Angelidis, I., Simon, L. M., Fernandez, I. E., Strunz, M., Mayr, C. H., Greiffo, F. R., et al. (2019). An atlas of the aging lung mapped by single cell transcriptomics and deep tissue proteomics. Nat. Commun. 10, 963. doi: 10.1038/s41467-019-08831-9

Astrup, A., Gøtzsche, P. C., van de Werken, K., Ranneries, C., Toubro, S., Raben, A., et al. (1999). Meta-analysis of resting metabolic rate in formerly obese subjects. Am. J. Clin. Nutr. 69, 1117-1122. doi: 10.1093/ajcn/69.6.1117 or weight re-gain after weight loss. The large heterogeneity of cell types in the CNS makes this a particularly challenging endeavor. Even neuronal subpopulations within a small region can show high diversity (Quiñones et al., 2018; Xu et al., 2018a). Moreover, neurons with their complex morphology based on long axonal connections and dendritic arborization show a high degree of interconnection and interspersion with other neuronal subpopulations and multiple glial cell types. Isolating and sorting individual CNS cell types can be achieved on a single cell (SC) and single nucleus (SN) level by FACS or immunopanning (IP). Genetic models that label individual cell types with a reporter can greatly improve this initial isolation and sorting step and subsequent epigenome profiling. Technological advances such as single cell RNAseq, ChIPmentation or Cut\&Run sequencing will accelerate that process (Schmidl et al., 2015; Krishnaswami et al., 2016; Macaulay et al., 2017; Skene et al., 2018). Overall, these techniques will contribute to our understanding of the weight cycling phenomenon, will help to identify novel pathways and targets in the CNS control of body weight, and will establish whether an epigenetic basis for the Yoyodieting phenomenon exists.

\section{AUTHOR CONTRIBUTIONS}

RC, SS and PP wrote and edited the manuscript.

\section{FUNDING}

This work has received funding from the European Union's Horizon 2020 Research and Innovation Programme under the Marie Skłodowska-Curie Grant Agreement No. 675610. This work was further supported in part by the DZD (SCS, PP), by the HelmholtzIsrael-Cooperation in Personalized Medicine (PP) and through the Initiative and Networking Fund of the Helmholtz Association.

\section{ACKNOWLEDGMENTS}

Elements of artwork used in Figure 1 were provided by Servier medical art under the creative commons license 3.0.

Barres, R., Kirchner, H., Rasmussen, M., Yan, J., Kantor, F. R., Krook, A., et al. (2013). Weight loss after gastric bypass surgery in human obesity remodels promoter methylation. Cell Rep. 3, 1020-1027. doi: 10.1016/j.celrep.2013.03.018 Barthelson, R. A., Lambert, G. M., Vanier, C., Lynch, R. M., and Galbraith, D. W. (2007). Comparison of the contributions of the nuclear and cytoplasmic compartments to global gene expression in human cells. BMC Genomics 8, 340 . doi: 10.1186/1471-2164-8-340

Bird, A. (1999). DNA Methylation de Novo. Science 286, 2287-2288. doi: 10.1126/ science.286.5448.2287

Bisagno, V., and Cadet, J. L. (2014). Stress, sex, and addiction: potential roles of corticotropin-releasing factor, oxytocin, and arginine-vasopressin. Behav. Pharmacol. 25, 445-457. doi: 10.1097/FBP.0000000000000049

Blundell, J. E., Caudwell, P., Gibbons, C., Hopkins, M., Naslund, E., King, N., et al. (2012). Role of resting metabolic rate and energy expenditure in hunger and appetite control: a new formulation. Dis. Model. Mech. 5, 608-613. doi: $10.1242 / \mathrm{dmm} .009837$

Bond, D. S., Phelan, S., Leahey, T. M., Hill, J. O., and Wing, R. R. (2009). Weightloss maintenance in successful weight losers: surgical vs non-surgical methods. Int. J. Obes. 2005 33, 173-180. doi: 10.1038/ijo.2008.256 
Bouchard, L., Rabasa-Lhoret, R., Faraj, M., Lavoie, M.-E., Mill, J., Pérusse, L., et al. (2010). Differential epigenomic and transcriptomic responses in subcutaneous adipose tissue between low and high responders to caloric restriction. Am. J. Clin. Nutr. 91, 309-320. doi: 10.3945/ajcn.2009.28085

Bueter, M., Löwenstein, C., Olbers, T., Wang, M., Cluny, N. L., Bloom, S. R., et al. (2010). Gastric bypass increases energy expenditure in rats. Gastroenterology 138, 1845-1853. doi: 10.1053/j.gastro.2009.11.012

Burger, K. S., and Stice, E. (2011). Relation of dietary restraint scores to activation of reward-related brain regions in response to food intake, anticipated intake, and food pictures. NeuroImage 55, 233-239. doi: 10.1016/j.neuroimage.2010.12.009

Cahoy, J. D., Emery, B., Kaushal, A., Foo, L. C., Zamanian, J. L., Christopherson, K. S., et al. (2008). A transcriptome database for astrocytes, neurons, and oligodendrocytes: a new resource for understanding brain development and function. J. Neurosci. Off. J. Soc. Neurosci. 28, 264-278. doi: 10.1523/ JNEUROSCI.4178-07.2008

Camps, S. G. J. A., Verhoef, S. P. M., and Westerterp, K. R. (2013). Weight loss, weight maintenance, and adaptive thermogenesis. Am. J. Clin. Nutr. 97, 990994. doi: 10.3945/ajcn.112.050310

Carhuatanta, K. A. K., Demuro, G., Tschöp, M. H., Pfluger, P. T., Benoit, S. C., and Obici, S. (2011). Voluntary exercise improves high-fat diet-induced leptin resistance independent of adiposity. Endocrinology 152, 2655-2664. doi: 10. 1210/en.2010-1340

Catenacci, V. A., Odgen, L., Phelan, S., Thomas, J. G., Hill, J., Wing, R. R., et al. (2014). Dietary habits and weight maintenance success in high versus low exercisers in the National Weight Control Registry. J. Phys. Act. Health 11, 1540-1548. doi: 10.1123/jpah.2012-0250

Caudwell, P., Finlayson, G., Gibbons, C., Hopkins, M., King, N., Näslund, E., et al. (2013). Resting metabolic rate is associated with hunger, self-determined meal size, and daily energy intake and may represent a marker for appetite. Am. J. Clin. Nutr. 97, 7-14. doi: 10.3945/ajcn.111.029975

Chambers, A. P., Kirchner, H., Wilson-Perez, H. E., Willency, J. A., Hale, J. E., Gaylinn, B. D., et al. (2013). The effects of vertical sleeve gastrectomy in rodents are ghrelin independent. Gastroenterology 144, 50-52.e5. doi: 10.1053/j. gastro.2012.09.009

Chhabra, K. H., Adams, J. M., Jones, G. L., Yamashita, M., Schlapschy, M., Skerra, A., et al. (2016). Reprogramming the body weight set point by a reciprocal interaction of hypothalamic leptin sensitivity and Pomc gene expression reverts extreme obesity. Mol. Metab. 5, 869-881. doi: 10.1016/j.molmet.2016.07.012

Corbett, S. W., Stern, J. S., and Keesey, R. E. (1986). Energy expenditure in rats with diet-induced obesity. Am. J. Clin. Nutr. 44, 173-180. doi: 10.1093/ajcn/44.2.173

Cordero, P., Campion, J., Milagro, F. I., Goyenechea, E., Steemburgo, T., Javierre, B. M., et al. (2011). Leptin and TNF-alpha promoter methylation levels measured by MSP could predict the response to a low-calorie diet. J. Physiol. Biochem. 67, 463-470. doi: 10.1007/s13105-011-0084-4

Cornier, M.-A., Grunwald, G. K., Johnson, S. L., and Bessesen, D. H. (2004). Effects of short-term overfeeding on hunger, satiety, and energy intake in thin and reduced-obese individuals. Appetite 43, 253-259. doi: 10.1016/j. appet.2004.06.003

Crujeiras, A. B., Goyenechea, E., Abete, I., Lage, M., Carreira, M. C., Martínez, J. A., et al. (2010). Weight regain after a diet-induced loss is predicted by higher baseline leptin and lower ghrelin plasma levels. J. Clin. Endocrinol. Metab. 95, 5037-5044. doi: 10.1210/jc.2009-2566

Dalgaard, K., Landgraf, K., Heyne, S., Lempradl, A., Longinotto, J., Gossens, K., et al. (2016). Trim28 Haploinsufficiency Triggers Bi-stable Epigenetic Obesity. Cell 164, 353-364. doi: 10.1016/j.cell.2015.12.025

Day, J. J., and Sweatt, J. D. (2011). Cognitive neuroepigenetics: a role for epigenetic mechanisms in learning and memory. Neurobiol. Learn. Mem. 96, 2-12. doi: 10.1016/j.nlm.2010.12.008

Deal, R. B., and Henikoff, S. (2011). The INTACT method for cell type-specific gene expression and chromatin profiling in Arabidopsis thaliana. Nat. Protoc. 6, 56-68. doi: 10.1038/nprot.2010.175

Ding, H., Douglass, E. F., Sonabend, A. M., Mela, A., Bose, S., Gonzalez, C., et al. (2018). Quantitative assessment of protein activity in orphan tissues and single cells using the metaVIPER algorithm. Nat. Commun. 9, 1471. doi: 10.1038/ s41467-018-03843-3

Doucet, E., St-Pierre, S., Alméras, N., Després, J. P., Bouchard, C., and Tremblay, A. (2001). Evidence for the existence of adaptive thermogenesis during weight loss. Br. J. Nutr. 85, 715-723. doi: 10.1079/BJN2001348
Doyle, J. P., Dougherty, J. D., Heiman, M., Schmidt, E. F., Stevens, T. R., Ma, G., et al. (2008). Application of a translational profiling approach for the comparative analysis of CNS cell types. Cell 135, 749-762. doi: 10.1016/j.cell.2008.10.029

Dulloo, A. G., and Montani, J.-P. (2015). Pathways from dieting to weight regain, to obesity and to the metabolic syndrome: an overview. Obes. Rev. Off. J. Int. Assoc. Study Obes. 16 Suppl 1, 1-6. doi: 10.1111/obr.12250

Egger, G., Liang, G., Aparicio, A., and Jones, P. A. (2004). Epigenetics in human disease and prospects for epigenetic therapy. Nature 429, 457-463. doi: 10. 1038 /nature 02625

Eraslan, G., Avsec, Ž., Gagneur, J., and Theis, F. J. (2019). Deep learning: new computational modelling techniques for genomics. Nat. Rev. Genet. 20, 389403. doi: 10.1038/s41576-019-0122-6

Farooqi, I. S., Jebb, S. A., Langmack, G., Lawrence, E., Cheetham, C. H., Prentice, A. M., et al. (1999). Effects of recombinant leptin therapy in a child with congenital leptin deficiency. N. Engl. J. Med. 341, 879-884. doi: 10.1056/ NEJM199909163411204

Farooqi, I. S., and O'Rahilly, S. (2008). Mutations in ligands and receptors of the leptin-melanocortin pathway that lead to obesity. Nat. Clin. Pract. Endocrinol. Metab. 4, 569-577. doi: 10.1038/ncpendmet0966

Fischer, D. S., Fiedler, A. K., Kernfeld, E. M., Genga, R. M. J., Bastidas-Ponce, A., Bakhti, M., et al. (2019). Inferring population dynamics from single-cell RNA-sequencing time series data. Nat. Biotechnol. 37, 461-468. doi: 10.1038/ s41587-019-0088-0

Fischer, I. P., Irmler, M., Meyer, C. W., Sachs, S. J., Neff, F., Hrabě de Angelis, M., et al. (2018). A history of obesity leaves an inflammatory fingerprint in liver and adipose tissue. Int. J. Obes. 2005 42, 507-517. doi: 10.1038/ijo.2017.224

Fothergill, E., Guo, J., Howard, L., Kerns, J. C., Knuth, N. D., Brychta, R., et al. (2016). Persistent metabolic adaptation 6 years after "The Biggest Loser" competition. Obes. Silver Spring Md 24, 1612-1619. doi: 10.1002/oby. 21538

Friedman, J. (2016). The long road to leptin. J. Clin. Invest. 126 (12), 4727-4734. doi: 10.1172/JCI91578

Froidevaux, F., Schutz, Y., Christin, L., and Jéquier, E. (1993). Energy expenditure in obese women before and during weight loss, after refeeding, and in the weight-relapse period. Am. J. Clin. Nutr. 57, 35-42. doi: 10.1093/ajcn/57.1.35

García-Cáceres, C., Quarta, C., Varela, L., Gao, Y., Gruber, T., Legutko, B., et al. (2016). Astrocytic insulin signaling couples brain glucose uptake with nutrient availability. Cell 166, 867-880. doi: 10.1016/j.cell.2016.07.028

Goldsmith, R., Joanisse, D. R., Gallagher, D., Pavlovich, K., Shamoon, E., Leibel, R. L., et al. (2010). Effects of experimental weight perturbation on skeletal muscle work efficiency, fuel utilization, and biochemistry in human subjects. Am. J. Physiol. Regul. Integr. Comp. Physiol. 298, R79-R88. doi: 10.1152/ ajpregu.00053.2009

González, B., Jayanthi, S., Gomez, N., Torres, O. V., Sosa, M. H., Bernardi, A., et al. (2018). Repeated methamphetamine and modafinil induce differential cognitive effects and specific histone acetylation and DNA methylation profiles in the mouse medial prefrontal cortex. Prog. Neuropsychopharmacol. Biol. Psychiatry 82, 1-11. doi: 10.1016/j.pnpbp.2017.12.009

Grindberg, R. V., Yee-Greenbaum, J. L., McConnell, M. J., Novotny, M., O'Shaughnessy, A. L., Lambert, G. M., et al. (2013). RNA-sequencing from single nuclei. Proc. Natl. Acad. Sci. U. S. A. 110, 19802-19807. doi: 10.1073/ pnas. 1319700110

Gupta-Agarwal, S., Franklin, A. V., Deramus, T., Wheelock, M., Davis, R. L., McMahon, L. L., et al. (2012). G9a/GLP histone lysine dimethyltransferase complex activity in the hippocampus and the entorhinal cortex is required for gene activation and silencing during memory consolidation. J. Neurosci. Off. J. Soc. Neurosci. 32, 5440-5453. doi: 10.1523/JNEUROSCI.0147-12.2012

Gupta-Agarwal, S., Jarome, T. J., Fernandez, J., and Lubin, F. D. (2014). NMDA receptor- and ERK-dependent histone methylation changes in the lateral amygdala bidirectionally regulate fear memory formation. Learn. Mem. Cold Spring Harb. N 21, 351-362. doi: 10.1101/lm.035105.114

Gustafsson, C., De Paepe, A., Schmidl, C., and Månsson, R. (2019). Highthroughput ChIPmentation: freely scalable, single day ChIPseq data generation from very low cell-numbers. BMC Genomics 20, 59. doi: 10.1186/ s12864-018-5299-0

Halaas, J. L., Boozer, C., Blair-West, J., Fidahusein, N., Denton, D. A., and Friedman, J. M. (1997). Physiological response to long-term peripheral and central leptin infusion in lean and obese mice. Proc. Natl. Acad. Sci. U. S. A. 94, 8878-8883. doi: 10.1073/pnas.94.16.8878 
Hames, K. C., Coen, P. M., King, W. C., Anthony, S. J., Stefanovic-Racic, M., Toledo, F. G. S., et al. (2016). Resting and exercise energy metabolism in weightreduced adults with severe obesity. Obes. Silver Spring Md 24, 1290-1298. doi: 10.1002/oby.21501

Hao, Z., Münzberg, H., Rezai-Zadeh, K., Keenan, M., Coulon, D., Lu, H., et al. (2015). Leptin deficient ob/ob mice and diet-induced obese mice responded differently to Roux-en-Y bypass surgery. Int. J. Obes. 2005 39, 798-805. doi: 10.1038/ijo.2014.189

Hao, Z., Zhao, Z., Berthoud, H.-R., and Ye, J. (2013). Development and verification of a mouse model for Roux-en-Y gastric bypass surgery with a small gastric pouch. PloS One 8, e52922. doi: 10.1371/journal.pone.0052922

Harrison, L., Schriever, S. C., Feuchtinger, A., Kyriakou, E., Baumann, P., Pfuhlmann, K., et al. (2018). Fluorescent blood-brain barrier tracing shows intact leptin transport in obese mice. Int. J. Obes. 43, 1305-1318. doi: 10.1038/ s41366-018-0221-z

Hatoum, I. J., Stylopoulos, N., Vanhoose, A. M., Boyd, K. L., Yin, D. P., Ellacott, K. L. J., et al. (2012). Melanocortin-4 receptor signaling is required for weight loss after gastric bypass surgery. J. Clin. Endocrinol. Metab. 97, E1023-E1031. doi: 10.1210/jc.2011-3432

He, W., Lam, T. K. T., Obici, S., and Rossetti, L. (2006). Molecular disruption of hypothalamic nutrient sensing induces obesity. Nat. Neurosci. 9, 227-233. doi: $10.1038 / \mathrm{nn} 1626$

Heijmans, B. T., Tobi, E. W., Stein, A. D., Putter, H., Blauw, G. J., Susser, E. S., et al. (2008). Persistent epigenetic differences associated with prenatal exposure to famine in humans. Proc. Natl. Acad. Sci. U. S. A. 105, 17046-17049. doi: 10.1073/pnas.0806560105

Heiman, M., Schaefer, A., Gong, S., Peterson, J., Day, M., Ramsey, K. E., et al. (2008). Development of a BACarray translational profiling approach for the molecular characterization of CNS cell types. Cell 135, 738-748. doi: 10.1016/j. cell.2008.10.028

Hermsdorff, H. H., Mansego, M. L., Campión, J., Milagro, F. I., Zulet, M. A., and Martínez, J. A. (2013). TNF-alpha promoter methylation in peripheral white blood cells: relationship with circulating TNFa, truncal fat and n-6 PUFA intake in young women. Cytokine 64, 265-271. doi: 10.1016/j.cyto.2013.05.028

Hill, J. O., Sparling, P. B., Shields, T. W., and Heller, P. A. (1987). Effects of exercise and food restriction on body composition and metabolic rate in obese women. Am. J. Clin. Nutr. 46, 622-630. doi: 10.1093/ajcn/46.4.622

Huang, Y.-T., Maccani, J. Z. J., Hawley, N. L., Wing, R. R., Kelsey, K. T., and McCaffery, J. M. (2015). Epigenetic patterns in successful weight loss maintainers: a pilot study. Int. J. Obes. 2005 39, 865-868. doi: 10.1038/ijo.2014.213

Jansson, J.-O., Palsdottir, V., Hägg, D. A., Schéle, E., Dickson, S. L., Anesten, F., et al. (2018). Body weight homeostat that regulates fat mass independently of leptin in rats and mice. Proc. Natl. Acad. Sci. U. S. A. 115, 427-432. doi: 10.1073/ pnas. 1715687114

Jayanthi, S., Gonzalez, B., McCoy, M. T., Ladenheim, B., Bisagno, V., and Cadet, J. L. (2018). Methamphetamine Induces TET1- and TET3-Dependent DNA Hydroxymethylation of Crh and Avp Genes in the Rat Nucleus Accumbens. Mol. Neurobiol. 55, 5154-5166. doi: 10.1007/s12035-017-0750-9

Jia, G., Preussner, J., Chen, X., Guenther, S., Yuan, X., Yekelchyk, M., et al. (2018). Single cell RNA-seq and ATAC-seq analysis of cardiac progenitor cell transition states and lineage settlement. Nat. Commun. 9, 4877. doi: 10.1038/ s41467-018-07307-6

Jiang, Y., Matevossian, A., Huang, H.-S., Straubhaar, J., and Akbarian, S. (2008). Isolation of neuronal chromatin from brain tissue. BMC Neurosci. 9, 42. doi: 10.1186/1471-2202-9-42

Karatsoreos, I. N., Thaler, J. P., Borgland, S. L., Champagne, F. A., Hurd, Y. L., and Hill, M. N. (2013). Food for thought: hormonal, experiential, and neural influences on feeding and obesity. J. Neurosci. 33, 17610-17616. doi: 10.1523/ JNEUROSCI.3452-13.2013

Kelesidis, T., Kelesidis, I., Chou, S., and Mantzoros, C. S. (2010). Narrative review: the role of leptin in human physiology: emerging clinical applications. Ann. Intern. Med. 152, 93-100. doi: 10.1059/0003-4819-152-2-201001190-00008

Kelley, K. W., Nakao-Inoue, H., Molofsky, A. V., and Oldham, M. C. (2018). Variation among intact tissue samples reveals the core transcriptional features of human CNS cell classes. Nat. Neurosci. 21, 1171. doi: 10.1038/s41593-018-0216-Z

Kelsey, G., Stegle, O., and Reik, W. (2017). Single-cell epigenomics: Recording the past and predicting the future. Science 358, 69-75. doi: 10.1126/science. aan 6826
Kennedy, G. C., and Sterling, P. A. (1953). The role of depot fat in the hypothalamic control of food intake in the rat. Proc. R. Soc. Lond. Ser. B Biol. Sci. 140, 578592. doi: 10.1098/rspb.1953.0009

Kim, J. G., Suyama, S., Koch, M., Jin, S., Argente-Arizon, P., Argente, J., et al. (2014). Leptin signaling in astrocytes regulates hypothalamic neuronal circuits and feeding. Nat. Neurosci. 17, 908-910. doi: 10.1038/nn.3725

Kirchner, H., Hofmann, S. M., Fischer-Rosinsky, A., Hembree, J., Abplanalp, W., Ottaway, N., et al. (2012). Caloric restriction chronically impairs metabolic programming in mice. Diabetes 61, 2734-2742. doi: 10.2337/db11-1621

Kissileff, H. R., Thornton, J. C., Torres, M. I., Pavlovich, K., Mayer, L. S., Kalari, V., et al. (2012). Leptin reverses declines in satiation in weight-reduced obese humans. Am. J. Clin. Nutr. 95, 309-317. doi: 10.3945/ajcn.111.012385

Knuth, N. D., Johannsen, D. L., Tamboli, R. A., Marks-Shulman, P. A., Huizenga, R., Chen, K. Y., et al. (2014). Metabolic adaptation following massive weight loss is related to the degree of energy imbalance and changes in circulating leptin. Obes. Silver Spring Md 22, 2563-2569. doi: 10.1002/oby.20900

Kohli, R., Bradley, D., Setchell, K. D., Eagon, J. C., Abumrad, N., and Klein, S. (2013). Weight loss induced by Roux-en-Y gastric bypass but not laparoscopic adjustable gastric banding increases circulating bile acids. J. Clin. Endocrinol. Metab. 98, E708-E712. doi: 10.1210/jc.2012-3736

Krishnaswami, S. R., Grindberg, R. V., Novotny, M., Venepally, P., Lacar, B., Bhutani, K., et al. (2016). Using single nuclei for RNA-seq to capture the transcriptome of postmortem neurons. Nat. Protoc. 11, 499-524. doi: 10.1038/nprot.2016.015

Kroeger, C. M., Hoddy, K. K., and Varady, K. A. (2014). Impact of weight regain on metabolic disease risk: a review of human trials. J. Obes. 2014, 614519. doi: 10.1155/2014/614519

Lake, B. B., Chen, S., Sos, B. C., Fan, J., Kaeser, G. E., Yung, Y. C., et al. (2018). Integrative single-cell analysis of transcriptional and epigenetic states in the human adult brain. Nat. Biotechnol. 36, 70-80. doi: 10.1038/nbt.4038

Lam, B. Y. H., Cimino, I., Polex-Wolf, J., Nicole, S. K., Rimmington, D., Iyemere, V., et al. (2017). Heterogeneity of hypothalamic pro-opiomelanocortin-expressing neurons revealed by single-cell RNA sequencing. Mol. Metab. 6, 383-392. doi: 10.1016/j.molmet.2017.02.007

Lam, T. K. T., Pocai, A., Gutierrez-Juarez, R., Obici, S., Bryan, J., Aguilar-Bryan, L., et al. (2005). Hypothalamic sensing of circulating fatty acids is required for glucose homeostasis. Nat. Med. 11, 320-327. doi: 10.1038/nm1201

le Roux, C. W., Aylwin, S. J. B., Batterham, R. L., Borg, C. M., Coyle, F., Prasad, V., et al. (2006). Gut hormone profiles following bariatric surgery favor an anorectic state, facilitate weight loss, and improve metabolic parameters. Ann. Surg. 243, 108-114.

Leibel, R. L., Rosenbaum, M., and Hirsch, J. (1995). Changes in energy expenditure resulting from altered body weight. N. Engl. J. Med. 332, 621-628. doi: 10.1056/ NEJM199503093321001

Lester, B. M., Tronick, E., Nestler, E., Abel, T., Kosofsky, B., Kuzawa, C. W., et al. (2011). Behavioral epigenetics. Ann. N. Y. Acad. Sci. 1226, 14-33. doi: 10.1111/j.1749-6632.2011.06037.x

Li, G., Zhang, W., Baker, M. S., Laritsky, E., Mattan-Hung, N., Yu, D., et al. (2014). Major epigenetic development distinguishing neuronal and non-neuronal cells occurs postnatally in the murine hypothalamus. Hum. Mol. Genet. 23, 15791590. doi: $10.1093 / \mathrm{hmg} / \mathrm{ddt} 548$

Lubin, F. D., Roth, T. L., and Sweatt, J. D. (2008). Epigenetic regulation of bdnf gene transcription in the consolidation of fear memory. J. Neurosci. 28, 10576 10586. doi: 10.1523/JNEUROSCI.1786-08.2008

Lutz, T. A., and Bueter, M. (2014). The physiology underlying Roux-en-Y gastric bypass: a status report. Am. J. Physiol. Regul. Integr. Comp. Physiol. 307, R1275R1291. doi: 10.1152/ajpregu.00185.2014

Macaulay, I. C., Ponting, C. P., and Voet, T. (2017). Single-cell multiomics: multiple measurements from single cells. Trends Genet. 33, 155-168. doi: 10.1016/j. tig.2016.12.003

Maclean, P. S., Bergouignan, A., Cornier, M.-A., and Jackman, M. R. (2011). Biology's response to dieting: the impetus for weight regain. Am. J. Physiol. Regul. Integr. Comp. Physiol. 301, R581-R600. doi: 10.1152/ajpregu.00755.2010

MacLean, P. S., Higgins, J. A., Johnson, G. C., Fleming-Elder, B. K., Peters, J. C., and Hill, J. O. (2004). Metabolic adjustments with the development, treatment, and recurrence of obesity in obesity-prone rats. Am. J. Physiol. Regul. Integr. Comp. Physiol. 287, R288-R297. doi: 10.1152/ajpregu.00010.2004

Maffei, M., Halaas, J., Ravussin, E., Pratley, R. E., Lee, G. H., Zhang, Y., et al. (1995). Leptin levels in human and rodent: measurement of plasma leptin and ob RNA in obese and weight-reduced subjects. Nat. Med. 1, 1155-1161. 
Martin, D., Xu, J., Porretta, C., and Nichols, C. D. (2017). Neurocytometry: flow cytometric sorting of specific neuronal populations from human and rodent brain. ACS Chem. Neurosci. 8, 356-367. doi: 10.1021/acschemneuro.6b00374

McGuire, M. T., Wing, R. R., and Hill, J. O. (1999). The prevalence of weight loss maintenance among American adults. Int. J. Obes. Relat. Metab. Disord. J. Int. Assoc. Study Obes. 23, 1314-1319. doi: 10.1038/sj.ijo.0801075

Melby, C. L., Paris, H. L., Foright, R. M., and Peth, J. (2017). Attenuating the biologic drive for weight regain following weight loss: must what goes down always go back up? Nutrients 9 (5): E468. doi: 10.3390/nu9050468

Melby, C. L., Schmidt, W. D., and Corrigan, D. (1990). Resting metabolic rate in weight-cycling collegiate wrestlers compared with physically active, noncycling control subjects. Am. J. Clin. Nutr. 52, 409-414. doi: 10.1093/ajcn/52.3.409

Milagro, F. I., Campión, J., Cordero, P., Goyenechea, E., Gómez-Uriz, A. M., Abete, I., et al. (2011). A dual epigenomic approach for the search of obesity biomarkers: DNA methylation in relation to diet-induced weight loss. FASEB J. Off. Publ. Fed. Am. Soc. Exp. Biol. 25, 1378-1389. doi: 10.1096/f.10-170365

Milagro, F. I., Gómez-Abellán, P., Campión, J., Martínez, J. A., Ordovás, J. M., and Garaulet, M. (2012). CLOCK, PER2 and BMAL1 DNA methylation: association with obesity and metabolic syndrome characteristics and monounsaturated fat intake. Chronobiol. Int. 29, 1180-1194. doi: 10.3109/07420528.2012.719967

Miller, C. A., Gavin, C. F., White, J. A., Parrish, R. R., Honasoge, A., Yancey, C. R., et al. (2010). Cortical DNA methylation maintains remote memory. Nat. Neurosci. 13, 664-666. doi: 10.1038/nn.2560

Mizuno, K., Dempster, E., Mill, J., and Giese, K. P. (2012). Long-lasting regulation of hippocampal Bdnf gene transcription after contextual fear conditioning. Genes Brain Behav. 11, 651-659. doi: 10.1111/j.1601-183X.2012.00805.x

Mo, A., Mukamel, E. A., Davis, F. P., Luo, C., Henry, G. L., Picard, S., et al. (2015). Epigenomic signatures of neuronal diversity in the mammalian brain. Neuron 86, 1369-1384. doi: 10.1016/j.neuron.2015.05.018

Moffitt, J. R., Bambah-Mukku, D., Eichhorn, S. W., Vaughn, E., Shekhar, K., Perez, J. D., et al. (2018). Molecular, spatial, and functional single-cell profiling of the hypothalamic preoptic region. Science (New York, N.Y.) 362 (6416): eaau5324. doi: 10.1126/science.aau5324

Mokadem, M., Zechner, J. F., Margolskee, R. F., Drucker, D. J., and Aguirre, V. (2014). Effects of Roux-en-Y gastric bypass on energy and glucose homeostasis are preserved in two mouse models of functional glucagon-like peptide-1 deficiency. Mol. Metab. 3, 191-201. doi: 10.1016/j.molmet.2013.11.010

Multhaup, M. L., Seldin, M. M., Jaffe, A. E., Lei, X., Kirchner, H., Mondal, P., et al. (2015). Mouse-human experimental epigenetic analysis unmasks dietary targets and genetic liability for diabetic phenotypes. Cell Metab. 21, 138-149. doi: 10.1016/j.cmet.2014.12.014

Myronovych, A., Kirby, M., Ryan, K. K., Zhang, W., Jha, P., Setchell, K. D., et al. (2014). Vertical sleeve gastrectomy reduces hepatic steatosis while increasing serum bile acids in a weight-loss-independent manner. Obes. Silver Spring Md 22, 390-400. doi: 10.1002/oby.20548

Näslund, E., Andersson, I., Degerblad, M., Kogner, P., Kral, J. G., Rössner, S., et al. (2000). Associations of leptin, insulin resistance and thyroid function with long-term weight loss in dieting obese men. J. Intern. Med. 248, 299-308. doi: 10.1046/j.1365-2796.2000.00737.x

Nicholas, L. M., Rattanatray, L., MacLaughlin, S. M., Ozanne, S. E., Kleemann, D. O., Walker, S. K., et al. (2013). Differential effects of maternal obesity and weight loss in the periconceptional period on the epigenetic regulation of hepatic insulin-signaling pathways in the offspring. FASEB J. Off. Publ. Fed. Am. Soc. Exp. Biol. 27, 3786-3796. doi: 10.1096/ff.13-227918

Nie, L., Shuai, L., Zhu, M., Liu, P., Xie, Z.-F., Jiang, S., et al. (2017). The landscape of histone modifications in a high-fat diet-induced obese (DIO) mouse model. Mol. Cell. Proteomics MCP 16, 1324-1334. doi: 10.1074/mcp.M117.067553

Obermann-Borst, S. A., Eilers, P. H., Tobi, E. W., De, F. J., Slagboom, P. E., Heijmans, B. T., et al. (2013). Duration of breastfeeding and gender are associated with methylation of the LEPTIN gene in very young children. Pediatr. Res. 74, 344349. doi: $10.1038 /$ pr.2013.95

Ottaway, N., Mahbod, P., Rivero, B., Norman, L. A., Gertler, A., D'Alessio, D., et al. (2015). Diet-induced obese mice retain endogenous leptin action. Cell Metab. 21, 877-882. doi: 10.1016/j.cmet.2015.04.015

Paden, C. M., Berglund, D. L., Hapner, S. J., and Welsh, C. J. (1986). A flow cytometric method for intracellular labeling and purification of rare neuronal populations: isolation of fixed neurophysin neurons. Brain Res. 376, 310-319. doi: 10.1016/0006-8993(86)90194-0
Paeger, L., Karakasilioti, I., Altmüller, J., Frommolt, P., Brüning, J., and Kloppenburg, P. (2017). Antagonistic modulation of NPY/AgRP and POMC neurons in the arcuate nucleus by noradrenalin. eLife 6, e25770. doi: 10.7554/ eLife. 25770

Pan, W. W., and Myers, M. G. Jr. (2018). Leptin and the maintenance of elevated body weight. Nat. Rev. Neurosci. 19, 95-105. doi: 10.1038/nrn.2017.168

Patti, M.-E., Houten, S. M., Bianco, A. C., Bernier, R., Larsen, P. R., Holst, J. J., et al. (2009). Serum bile acids are higher in humans with prior gastric bypass: potential contribution to improved glucose and lipid metabolism. Obes. Silver Spring Md 17, 1671-1677. doi: 10.1038/oby.2009.102

Peat, J. R., and Smallwood, S. A. (2018). Low input whole-genome bisulfite sequencing using a post-bisulfite adapter tagging approach. Methods Mol. Biol. Clifton NJ 1708, 161-169. doi: 10.1007/978-1-4939-7481-8_9

Plass, M., Solana, J., Wolf, F. A., Ayoub, S., Misios, A., Glažar, P., et al. (2018). Cell type atlas and lineage tree of a whole complex animal by single-cell transcriptomics. Science (New York, N.Y.) 360 (6391): eaaq1723. doi: 10.1126/science.aaq1723

Quiñones, M., Al-Massadi, O., Folgueira, C., Bremser, S., Gallego, R., TorresLeal, L., et al. (2018). p53 in AgRP neurons is required for protection against diet-induced obesity via JNK1. Nat. Commun. 9, 3432. doi: 10.1038/ s41467-018-05711-6

Ravelli, A. C., van der Meulen, J. H., Michels, R. P., Osmond, C., Barker, D. J., Hales, C. N., et al. (1998). Glucose tolerance in adults after prenatal exposure to famine. Lancet Lond. Engl. 351, 173-177. doi: 10.1016/s0140-6736(97)07244-9

Ravussin, Y., LeDuc, C. A., Watanabe, K., Mueller, B. R., Skowronski, A., Rosenbaum, M., et al. (2014). Effects of chronic leptin infusion on subsequent body weight and composition in mice: can body weight set point be reset? Mol. Metab. 3, 432-440. doi: 10.1016/j.molmet.2014.02.003

Renthal, W., Maze, I., Krishnan, V., Covington, H. E., Xiao, G., Kumar, A., et al. (2007). Histone deacetylase 5 epigenetically controls behavioral adaptations to chronic emotional stimuli. Neuron 56, 517-529. doi: 10.1016/j. neuron.2007.09.032

Rönn, T., Volkov, P., Davegårdh, C., Dayeh, T., Hall, E., Olsson, A. H., et al. (2013). A six months exercise intervention influences the genome-wide DNA methylation pattern in human adipose tissue. PLoS Genet. 9, e1003572. doi: 10.1371/journal.pgen.1003572

Rosenbaum, M., Goldsmith, R., Bloomfield, D., Magnano, A., Weimer, L., Heymsfield, S., et al. (2005). Low-dose leptin reverses skeletal muscle, autonomic, and neuroendocrine adaptations to maintenance of reduced weight. J. Clin. Invest. 115, 3579-3586. doi: 10.1172/JCI25977

Rosenbaum, M., Hirsch, J., Gallagher, D. A., and Leibel, R. L. (2008). Long-term persistence of adaptive thermogenesis in subjects who have maintained a reduced body weight. Am. J. Clin. Nutr. 88, 906-912. doi: 10.1093/ajcn/88.4.906

Rosenbaum, M., Kissileff, H. R., Mayer, L. E. S., Hirsch, J., and Leibel, R. L. (2010). Energy intake in weight-reduced humans. Brain Res. 1350, 95-102. doi: 10.1016/j.brainres.2010.05.062

Ryan, K. K., Tremaroli, V., Clemmensen, C., Kovatcheva-Datchary, P., Myronovych, A., Karns, R., et al. (2014). FXR is a molecular target for the effects of vertical sleeve gastrectomy. Nature 509, 183-188. doi: 10.1038/nature13135

Schaap, F. G. (2012). Role of fibroblast growth factor 19 in the control of glucose homeostasis. Curr. Opin. Clin. Nutr. Metab. Care 15, 386-391. doi: 10.1097/ MCO.0b013e3283547171

Schmidl, C., Rendeiro, A. F., Sheffield, N. C., and Bock, C. (2015). ChIPmentation: fast, robust, low-input ChIP-seq for histones and transcription factors. Nat. Methods 12, 963-965. doi: 10.1038/nmeth.3542

Schwartz, M. W., Peskind, E., Raskind, M., Boyko, E. J., and Porte, D. (1996). Cerebrospinal fluid leptin levels: relationship to plasma levels and to adiposity in humans. Nat. Med. 2, 589. doi: 10.1038/nm0596-589

Seki, Y., Williams, L., Vuguin, P. M., and Charron, M. J. (2012). Minireview: epigenetic programming of diabetes and obesity: animal models. Endocrinology 153, 1031-1038. doi: 10.1210/en.2011-1805

Skene, P. J., Henikoff, J. G., and Henikoff, S. (2018). Targeted in situ genome-wide profiling with high efficiency for low cell numbers. Nat. Protoc. 13, 1006-1019. doi: $10.1038 /$ nprot.2018.015

Skene, P. J., and Henikoff, S. (2017). An efficient targeted nuclease strategy for high-resolution mapping of DNA binding sites. eLife 6, e21856. doi: 10.7554/ eLife. 21856

Smallwood, S. A., and Kelsey, G. (2012). De novo DNA methylation: a germ cell perspective. Trends Genet. 28, 33-42. doi: 10.1016/j.tig.2011.09.004 
Solnestam, B. W., Stranneheim, H., Hällman, J., Käller, M., Lundberg, E., Lundeberg, J., et al. (2012). Comparison of total and cytoplasmic mRNA reveals global regulation by nuclear retention and miRNAs. BMC Genomics 13, 574. doi: 10.1186/1471-2164-13-574

Speakman, J. R. (2007). A nonadaptive scenario explaining the genetic predisposition to obesity: the "predation release" hypothesis. Cell Metab. 6, 5-12. doi: 10.1016/j.cmet.2007.06.004

Speakman, J. R. (2018). Why lipostatic set point systems are unlikely to evolve. Mol. Metab. 7, 147-154. doi: 10.1016/j.molmet.2017.10.007

Stefater, M. A., Pérez-Tilve, D., Chambers, A. P., Wilson-Pérez, H. E., Sandoval, D. A., Berger, J., et al. (2010). Sleeve gastrectomy induces loss of weight and fat mass in obese rats, but does not affect leptin sensitivity. Gastroenterology 138, 2426-2436.e3. doi: 10.1053/j.gastro.2010.02.059

Stein, A. D., Kahn, H. S., Rundle, A., Zybert, P. A., van der Pal-de Bruin, K., and Lumey, L. H. (2007). Anthropometric measures in middle age after exposure to famine during gestation: evidence from the Dutch famine. Am. J. Clin. Nutr. 85, 869-876. doi: 10.1093/ajcn/85.3.869

Sumithran, P., Prendergast, L. A., Delbridge, E., Purcell, K., Shulkes, A., Kriketos, A., et al. (2011). Long-term persistence of hormonal adaptations to weight loss. N. Engl. J. Med. 365, 1597-1604. doi: 10.1056/NEJMoa1 105816

Tritschler, S., Theis, F. J., Lickert, H., and Böttcher, A. (2017). Systematic single-cell analysis provides new insights into heterogeneity and plasticity of the pancreas. Mol. Metab. 6, 974-990. doi: 10.1016/j.molmet.2017.06.021

Trujillo, J. M., Nuffer, W., and Ellis, S. L. (2015). GLP-1 receptor agonists: a review of head-to-head clinical studies. Ther. Adv. Endocrinol. Metab. 6, 19-28. doi: 10.1177/2042018814559725

van Dijk, S. J., Molloy, P. L., Varinli, H., Morrison, J. L., and Muhlhausler, B. S.Members of EpiSCOPE (2015). Epigenetics and human obesity. Int. J. Obes. 2005 39, 85-97. doi: 10.1038/ijo.2014.34

Vodnik, M., Štrukelj, B., and Lunder, M. (2016). Ghrelin receptor ligands reaching clinical trials: from peptides to peptidomimetics; from agonists to antagonists. Horm. Metab. Res. Horm. Stoffwechselforschung Horm. Metab. 48, 1-15. doi: 10.1055/s-0035-1564149

Vucetic, Z., Carlin, J. L., Totoki, K., and Reyes, T. M. (2012). Epigenetic dysregulation of the dopamine system in diet-induced obesity. J. Neurochem. 120, 891-898. doi: 10.1111/j.1471-4159.2012.07649.x

Vucetic, Z., Kimmel, J., and Reyes, T. M. (2011). Chronic high-fat diet drives postnatal epigenetic regulation of $\mu$-opioid receptor in the brain. Neuropsychopharmacol. Off. Publ. Am. Coll. Neuropsychopharmacol. 36, 1199-1206. doi: 10.1038/npp.2011.4

Waterson, M. J., and Horvath, T. L. (2015). Neuronal regulation of energy homeostasis: beyond the hypothalamus and feeding. Cell Metab. 22, 962-970. doi: 10.1016/j.cmet.2015.09.026

Weiss, E. C., Galuska, D. A., Kettel Khan, L., Gillespie, C., and Serdula, M. K. (2007). Weight regain in U.S. adults who experienced substantial weight loss, 1999-2002. Am. J. Prev. Med. 33, 34-40. doi: 10.1016/j.amepre.2007.02.040

Wen, L., and Tang, F. (2018). Single cell epigenome sequencing technologies. Mol. Aspects Med. 59, 62-69. doi: 10.1016/j.mam.2017.09.002

Wilson-Pérez, H. E., Chambers, A. P., Ryan, K. K., Li, B., Sandoval, D. A., Stoffers, D., et al. (2013). Vertical sleeve gastrectomy is effective in two genetic mouse models of glucagon-like Peptide 1 receptor deficiency. Diabetes 62, 2380-2385. doi: $10.2337 / \mathrm{db} 12-1498$

Wing, R. R., and Hill, J. O. (2001). Successful weight loss maintenance. Annu. Rev. Nutr. 21, 323-341. doi: 10.1146/annurev.nutr.21.1.323

Wing, R. R., and Phelan, S. (2005). Long-term weight loss maintenance. Am. J. Clin. Nutr. 82, 222S-225S. doi: 10.1093/ajcn/82.1.222S

World Health Organization (2018). World Health Organization. http://www.who. int/news-room/fact-sheets/detail/obesity-and-overweight.

Wu, X., Ge, H., Baribault, H., Gupte, J., Weiszmann, J., Lemon, B., et al. (2013). Dual actions of fibroblast growth factor 19 on lipid metabolism. J. Lipid Res. 54, 325-332. doi: 10.1194/jlr.M027094

Xu, J., Bartolome, C. L., Low, C. S., Yi, X., Chien, C.-H., Wang, P., et al. (2018a). Genetic identification of leptin neural circuits in energy and glucose homeostases. Nature 556, 505-509. doi: 10.1038/s41586-018-0049-7

Xu, X., Stoyanova, E. I., Lemiesz, A. E., Xing, J., Mash, D. C., and Heintz, N. (2018b). Species and cell-type properties of classically defined human and rodent neurons and glia. eLife 7, e37551. doi: 10.7554/eLife.37551

Ye, J., Hao, Z., Mumphrey, M. B., Townsend, R. L., Patterson, L. M., Stylopoulos, N., et al. (2014). GLP-1 receptor signaling is not required for reduced body weight after RYGB in rodents. Am. J. Physiol. Regul. Integr. Comp. Physiol. 306, R352R362. doi: 10.1152/ajpregu.00491.2013

Zechner, J. F., Mirshahi, U. L., Satapati, S., Berglund, E. D., Rossi, J., Scott, M. M., et al. (2013). Weight-independent effects of roux-en-Y gastric bypass on glucose homeostasis via melanocortin-4 receptors in mice and humans. Gastroenterology 144, 580-590.e7. doi: 10.1053/j.gastro.2012.11.022

Zeisel, A., Muñoz-Manchado, A. B., Codeluppi, S., Lönnerberg, P., La Manno, G., Juréus, A., et al. (2015). Brain structure. Cell types in the mouse cortex and hippocampus revealed by single-cell RNA-seq. Science 347, 1138-1142. doi: $10.1126 /$ science.aaa1934

Zhang, S., Rattanatray, L., MacLaughlin, S. M., Cropley, J. E., Suter, C. M., Molloy, L., et al. (2010). Periconceptional undernutrition in normal and overweight ewes leads to increased adrenal growth and epigenetic changes in adrenal IGF2/H19 gene in offspring. FASEB J. Off. Publ. Fed. Am. Soc. Exp. Biol. 24, 2772-2782. doi: 10.1096/fj.09-154294

Zhang, Y., Proenca, R., Maffei, M., Barone, M., Leopold, L., and Friedman, J. M. (1994). Positional cloning of the mouse obese gene and its human homologue. Nature 372, 425. doi: 10.1038/372425a0

Conflict of Interest: The authors declare that the research was conducted in the absence of any commercial or financial relationships that could be construed as a potential conflict of interest.

Copyright (c) 2019 Contreras, Schriever and Pfluger. This is an open-access article distributed under the terms of the Creative Commons Attribution License (CC $B Y)$. The use, distribution or reproduction in other forums is permitted, provided the original author(s) and the copyright owner(s) are credited and that the original publication in this journal is cited, in accordance with accepted academic practice. No use, distribution or reproduction is permitted which does not comply with these terms. 